\title{
Personalized antibiotic dosing for the critically ill
}

\author{
Jason A. Roberts $1,2,3,4^{*}$ (D) Claire Roger ${ }^{5}$ and Jan J. De Waele ${ }^{6}$
}

(c) 2019 Springer-Verlag GmbH Germany, part of Springer Nature

Therapeutic antibiotic exposures (concentrations) have been demonstrated to improve clinical cure, reduce drug toxicity and even reduce mortality in infected critically ill patients [1-3]. With persisting high morbidity and mortality associated with sepsis and septic shock in these patients, optimisation of antibiotic exposures is a key treatment intervention. However, there are various patient, diagnostic, treatment and pathology-related factors which complicate this process. A dosing strategy that is personalised to the individual's needs is required during critical illness to ensure these exposures associated with patient benefit are achieved [4].

This article will review some of the data that associate antibiotic exposure with clinical benefit, or toxicity; present the challenges to effective treatment and provide a paradigm for a more personalised approach to treatment that has a higher likelihood of achieving therapeutic antibiotic exposures.

There are numerous studies for a wide range of antibiotics in various infection syndromes, including pneumonia, blood stream infection and septic shock, associating antibiotic exposure (expressed as pharmacokinetic/pharmacodynamic (PK/PD) indices) with patient outcome [3, $5,6]$. These data transcend beta-lactams, carbapenems, quinolones, vancomycin, linezolid, aminoglycosides and

*Correspondence: j.roberts2@uq.edu.au

${ }^{1}$ University of Queensland Centre for Clinical Research, The University of Queensland, Brisbane, Australia

Full author information is available at the end of the article

This Editorial is dedicated to the ongoing research and training career of Professor Jeffrey Lipman, The University of Queensland and Royal Brisbane and Women's Hospital. Prof Lipman is the pioneer in antimicrobial dosing in the critically ill and has mentored many international leading researchers in this field and gave a Keynote Presentation on this topic at the 2018 European Society of Intensive Care Medicine Annual Meeting in Paris. tigecycline $[1,3,4]$. Although all these studies are from retrospective clinical evaluations of data from previous pharmacokinetic studies, the information aligns closely with mechanistic in vitro studies and has strong biological plausibility [4]. In vitro data describing antibiotic exposures that can suppress emergence of resistance also are available [7], although these have not been systematically studied clinically. Furthermore, data associating excessive drug exposures with drug-related toxicity is also accessible [8]. To this end, using an approach to antibiotic dosing that ensures achievement of these drug exposures, often measured as unbound drug, associated with improved patient outcomes has been recommended in leading international clinical practice guidelines of the management of adults with hospital-acquired and ventilator-associated pneumonia $[9,10]$.

A prominent challenge for achieving target antibiotic exposures, is antibiotic pharmacokinetic variability, which causes optimal doses to be difficult to predict. Whilst much pharmacokinetic variability is driven by dramatic variations in drug clearance from changes in predominantly renal function, from augmented renal clearance (a supranormal creatinine clearance driven by systemic inflammatory response to infection) to severe acute kidney injury. Changes in the volume of distribution of hydrophilic antibiotics like beta-lactams, aminoglycosides and glycopeptides can also affect the magnitude of dose required. Finally, use of extracorporeal therapies including renal replacement therapy and extracorporeal membrane oxygenation can have difficult to predict effects on antibiotic dosing requirements [4].

A further challenge for ensuring optimal antibiotic exposures is that these are contingent on the susceptibility of the pathogen, which is described as the minimum inhibitory concentration (MIC) of the bacteria to the selected antibiotic. Epidemiological studies have shown that critically ill patients very commonly are infected by

\section{实



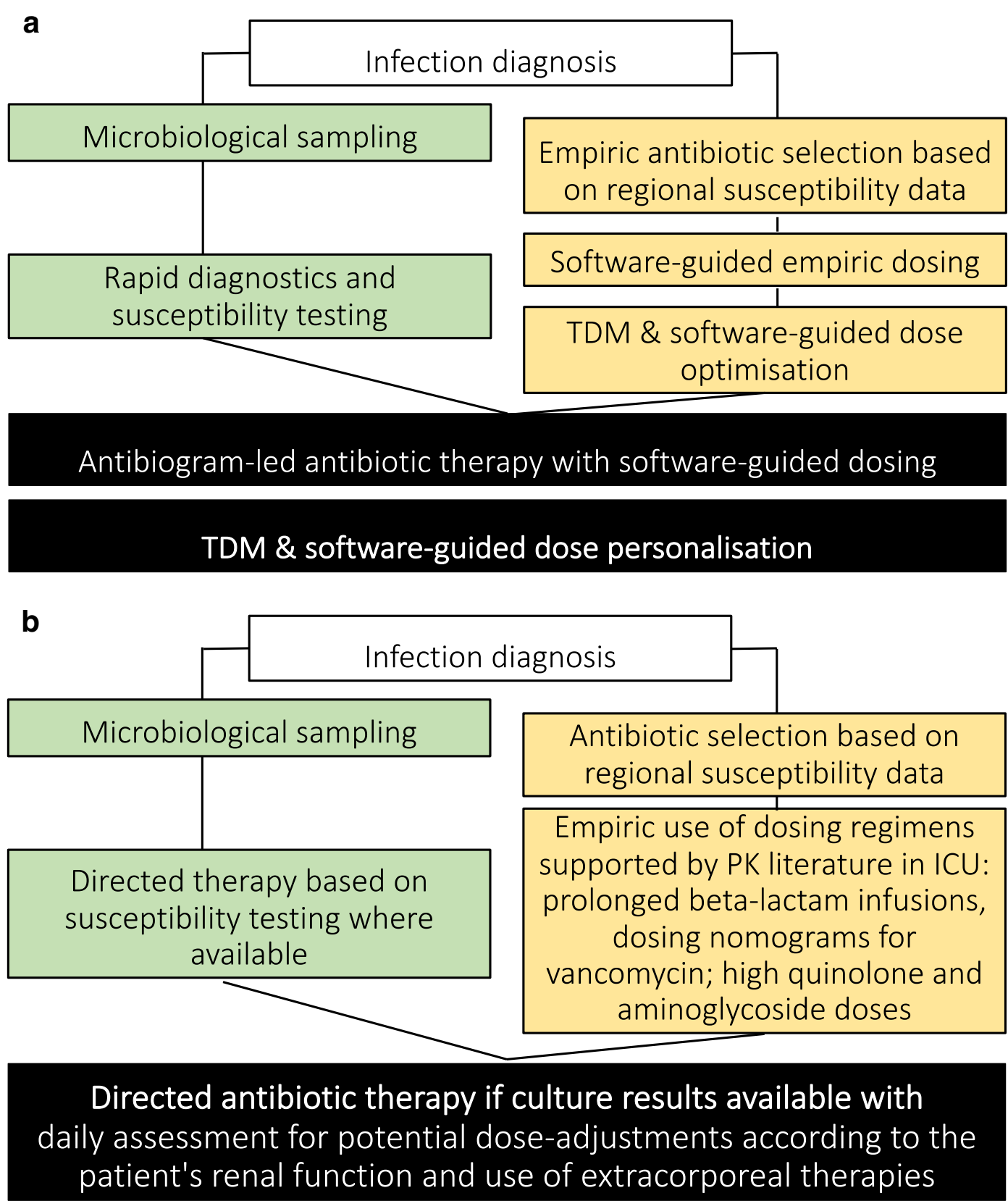

Fig. 1 a An optimal process for dose personalisation using rapid diagnostics and antibiotic susceptibility testing, dosing software and therapeutic drug monitoring (TDM); $\mathbf{b}$ a process for dose personalisation in resource poor settings

less susceptible pathogens [11]. In this scenario, the MIC, or denominator of the PK/PD index is higher, requiring a higher PK exposure (numerator) to ensure the minimum PK/PD index is achieved. That is, a higher dose is required to treat for less susceptible pathogens. It should be noted that use of MICs to guide antibiotic doses in individual patients is considered problematic because of the delay in reporting and variability in laboratory testing results. To account for these challenges, Mouton et al. have recommended that where the MIC is below the susceptibility breakpoint, that the breakpoint value should be used as the denominator in the PK/PD index. 
However, where the MIC exceeds breakpoint, a value two dilutions higher than that reported, is recommended (i.e., reported MIC $4 \mathrm{mg} / \mathrm{L}$ where breakpoint is $2 \mathrm{mg} / \mathrm{L}$, then use $16 \mathrm{mg} / \mathrm{L}$ ) [12].

Knowledge of PK/PD (drug exposure relative to pathogen susceptibility) is vital to personalising antibiotic dosing, but obtaining this data in a timely manner is essential given the high level of sickness of severity of critically ill patients. To this end, advancing beyond traditional antibiotic susceptibility testing methods is required as these may take 48-96 h to provide definitive characterisation of a cultured organism and application of microbiological rapid diagnostics (e.g., multiplex PCR testing and rapid whole genome sequencing) is needed.

Achieving effective antibiotic exposures by assessing a patient's needs at the bedside does not result in consistent achievement of therapeutic concentrations [2]. As such, various alternative approaches to dosing should be considered. Firstly, through use of unit-level interventions (e.g., prolonged infusions of beta-lactams [5]). Secondly, use of nomograms that recommend doses using patient renal function or body weight [13]. Thirdly, dosing software that applies knowledge of the effect of patient characteristics on dosing requirements [6]. Fourthly, therapeutic drug monitoring (TDM) to measure drug exposures and then adjust dosing, as needed, to achieve therapeutic exposures [14]. Finally, combining TDM with dosing software and apply Bayesian forecasting for more sophisticated dose adjustment [15]. Use of any of the final three dosing interventions remains uncommon, yet represents the approaches most likely to ensure personalised doses that most consistently achieve therapeutic exposures.

Application of PK/PD to personalise antibiotic dosing can be performed in any patient regardless of the resources available to the hospital or clinician [1]. More resources, of course, will increase the sophistication of the approach to dose optimisation. In the future, it is likely that a highly sophisticated approach to accurate dosing could be applied (Fig. 1). This approach would use effective empiric antibiotic doses using dosing software, supplemented by rapid diagnostics and susceptibility testing to guide optimal antibiotic selection for the causative pathogen. Empiric dosing of directed antibiotic therapy would again use dosing software, with subsequent dosing optimised using an iterative process of TDM combined with Bayesian forecasting within dosing software [4]. Targets could be set at maximal bacterial killing or suppression of resistance, depending on the probability of drug toxicity that would increase with higher drug exposures.

In conclusion, antibiotic dosing in critically ill patients is highly challenging, but should be considered a key intervention to further improve infection-related outcomes. To this end, a more personalised approach to drug dosing, which understands pharmacokinetics in the individual patient and pathogen susceptibility (MIC), is required. Using dosing interventions, including application of dosing software and TDM, it is possible to ensure more patients achieve target drug exposures. To date, this has not been widely investigated, and trials to quantify to what extent this intervention can increase clinical cure and patient survival, or even reduce emergence of antibiotic resistance, are eagerly anticipated.

\section{Author details \\ ${ }^{1}$ University of Queensland Centre for Clinical Research, The University of Queensland, Brisbane, Australia. ${ }^{2}$ Centre of Translational Anti-infective Pharmacodynamics, School of Pharmacy, The University of Queensland, Brisbane, Australia. ${ }^{3}$ Department of Intensive Care Medicine, Royal Brisbane and Women's Hospital, Brisbane, Australia. ${ }^{4}$ Pharmacy Department, Royal Brisbane and Women's Hospital, Brisbane, Australia. ${ }^{5}$ Service des réanimations, Pôle Anesthésie Réanimation Douleur Urgence, CHU Nîmes, Nîmes, France. ${ }^{6}$ Department of Critical Care Medicine, Ghent University Hospital, Ghent, Belgium.}

\section{Acknowledgements}

J.A.R. received salary funding from the National Health and Medical Research Council of Australia; Practitioner Fellowship (APP1117065). We wish to acknowledge funding from the Australian National Health and Medical Research Council for a Centre of Research Excellence (APP1099452) and a Project Grant (APP1044941). J. De Waele is Senior Clinical Investigator at the Research Foundation Flanders (FWO, ref. 1881015N).

\section{Compliance with ethical standards}

\section{Conflicts of interest}

The authors have no known conflicts of interest relating to this work. JA Roberts declares unrelated consultancies for bioMerieux, MSD, Astellas and Infectopharm over the last 3 years. C Roger declares unrelated travel grants from MSD, Pfizer over the last 3 years. J De Waele declares unrelated consultancies for Accelerate, MSD, Bayer Healthcare, Pfizer, and Grifols.

\section{Publisher's Note}

Springer Nature remains neutral with regard to jurisdictional claims in published maps and institutional affiliations.

Received: 31 October 2018 Accepted: 6 January 2019

Published online: 14 January 2019

\section{References}

1. Tangden T, Ramos Martin V, Felton TW, Nielsen El, Marchand S, Bruggemann RJ, Bulitta JB, Bassetti M, Theuretzbacher U, Tsuji BT, Wareham DW, Friberg LE, De Waele JJ, Tam VH, Roberts JA, Infection Section for the European Society of Intensive Care Medicine tP, Pharmacodynamics Study Group of the European Society of Clinical M, Infectious Diseases tISoA-IP, the Critically III Patients Study Group of European Society of Clinical M, Infectious D (2017) The role of infection models and PK/PD modelling for optimising care of critically ill patients with severe infections. Intensive Care Med 43:1021-1032

2. Roberts JA, Paul SK, Akova M, Bassetti M, De Waele JJ, Dimopoulos G, Kaukonen KM, Koulenti D, Martin C, Montravers P, Rello J, Rhodes A, Starr T, Wallis SC, Lipman J, Study D (2014) DALI: defining antibiotic levels in intensive care unit patients: are current beta-lactam antibiotic doses sufficient for critically ill patients? Clin Infect Dis 58:1072-1083 
3. Li C, Du X, Kuti JL, Nicolau DP (2007) Clinical pharmacodynamics of meropenem in patients with lower respiratory tract infections. Antimicrob Agents Chemother 51:1725-1730

4. Roberts JA, Abdul-Aziz MH, Lipman J, Mouton JW, Vinks AA, Felton TW, Hope WW, Farkas A, Neely MN, Schentag JJ, Drusano G, Frey OR, Theuretzbacher U, Kuti JL (2014) Individualised antibiotic dosing for patients who are critically ill: challenges and potential solutions. Lancet Infect Dis 14:498-509

5. Dulhunty JM, Roberts JA, Davis JS, Webb SA, Bellomo R, Gomersall C, Shirwadkar C, Eastwood GM, Myburgh J, Paterson DL, Starr T, Paul SK, Lipman J (2015) A multicenter randomized trial of continuous versus intermittent beta-lactam infusion in severe sepsis. Am J Respir Crit Care Med 192:1298-1305

6. Heil EL, Nicolau DP, Farkas A, Roberts JA, Thom KA (2018) Pharmacodynamic target attainment for cefepime, meropenem, and piperacillintazobactam using a pharmacokinetic/pharmacodynamic-based dosing calculator in critically ill patients. Antimicrob Agents Chemother 62:e01008-18

7. Bergen PJ, Bulitta JB, Kirkpatrick CMJ, Rogers KE, McGregor MJ, Wallis SC, Paterson DL, Nation RL, Lipman J, Roberts JA, Landersdorfer CB (2017) Substantial impact of altered pharmacokinetics in critically ill patients on the antibacterial effects of meropenem evaluated via the dynamic hollow-fiber infection model. Antimicrob Agents Chemother 61

8. Beumier M, Casu GS, Hites M, Wolff F, Cotton F, Vincent JL, Jacobs F, Taccone FS (2015) Elevated beta-lactam concentrations associated with neurological deterioration in ICU septic patients. Minerva Anestesiol 81:497-506

9. Kalil AC, Metersky ML, Klompas M, Muscedere J, Sweeney DA, Palmer LB, Napolitano LM, O'Grady NP, Bartlett JG, Carratala J, El Solh AA, Ewig S, Fey PD, File TM Jr, Restrepo MI, Roberts JA, Waterer GW, Cruse P, Knight SL, Brozek JL (2016) Executive Summary: management of Adults With Hospital-acquired and Ventilator-associated Pneumonia: 2016 Clinical Practice Guidelines by the Infectious Diseases Society of America and the American Thoracic Society. Clin Infect Dis 63:575-582
10. Rhodes A, Evans LE, Alhazzani W, Levy MM, Antonelli M, Ferrer R, Kumar A, Sevransky JE, Sprung CL, Nunnally ME, Rochwerg B, Rubenfeld GD, Angus DC, Annane D, Beale RJ, Bellinghan GJ, Bernard GR, Chiche JD, Coopersmith C, De Backer DP, French CJ, Fujishima S, Gerlach H, Hidalgo JL, Hollenberg SM, Jones AE, Karnad DR, Kleinpell RM, Koh Y, Lisboa TC, Machado FR, Marini JJ, Marshall JC, Mazuski JE, McIntyre LA, McLean AS, Mehta S, Moreno RP, Myburgh J, Navalesi P, Nishida O, Osborn TM, Perner A, Plunkett CM, Ranieri M, Schorr CA, Seckel MA, Seymour CW, Shieh L, Shukri KA, Simpson SQ, Singer M, Thompson BT, Townsend SR, Van der Poll T, Vincent JL, Wiersinga WJ, Zimmerman JL, Dellinger RP (2017) Surviving Sepsis Campaign: International Guidelines for Management of Sepsis and Septic Shock: 2016. Intensive Care Med

11. Valenza G, Seifert H, Decker-Burgard S, Laeuffer J, Morrissey I, Mutters R (2012) Comparative activity of carbapenem testing (COMPACT) study in Germany. Int J Antimicrob Agents 39:255-258

12. Mouton JW, Muller AE, Canton R, Giske CG, Kahlmeter G, Turnidge J (2018) MIC-based dose adjustment: facts and fables. J Antimicrob Chemother 73:564-568

13. Pea F, Viale P, Cojutti P, Furlanut M (2012) Dosing nomograms for attaining optimum concentrations of meropenem by continuous infusion in critically ill patients with severe gram-negative infections: a pharmacokinetics/pharmacodynamics-based approach. Antimicrob Agents Chemother 56:6343-6348

14. Wong G, Briscoe S, McWhinney B, Ally M, Ungerer J, Lipman J, Roberts JA (2018) Therapeutic drug monitoring of b-lactam antibiotics in the critically ill: direct measurement of unbound drug concentrations to achieve appropriate drug exposures. J Antimicrob Chemother in press

15. Neely MN, Kato L, Youn G, Kraler L, Bayard D, van Guilder M, Schumitzky A, Yamada W, Jones B, Minejima E (2018) Prospective trial on the use of trough concentration versus area under the curve to determine therapeutic vancomycin dosing. Antimicrob Agents Chemother 62 